\title{
ЛИНГВОКУЛЬТУРОЛОГИЧЕСКИЕ ОСОБЕННОСТИ СОВЕТСКОГО И СОВРЕМЕННОГО РЕКЛАМНОГО ДИСКУРСА
}

\section{LINGUISTIC AND CULTURAL FEATURES OF THE SOVIET AND MODERN ADVERTISING DISCOURSE}

Nguyen Thi Van Anh

Summary: This article examines the concepts of "discourse» and "advertising discourse», analyzes in detail the texts of commercial advertising of the Soviet and modern period for the subject of linguistic and cultural features. As a result of the analysis, the author identified common and special linguistic and cultural features of Soviet and modern advertising, which are directly related to external factors (political, historical, economic, etc.). So, in the Soviet period, the main purpose of advertising, due to the lack of competition, was to inform the population about new goods and services. In this regard, it was not the manufacturers who were advertised, but the goods. For the same reason, primitive slogans were used. In the early $90 \mathrm{~s}$, in the era of imitation of the West, texts began to be full of Anglicisms. Since the 90 s, advertising has pursued one main goal: to sell. While the characters played an important role in creating an advertising culture for consumers, the product was always in the foreground. This continued until online advertising appeared, and with it several important changes in the development of advertising and personalization.

Keywords: advertising discourse, linguoculturology, personalization, imperatives, personification, deviations.
Нгуен Тхи Ван Ань

Аспирант, Институт русского языка имени А.С. Пушкина vananhrussia95@gmail.com

Аннотация: В данной статье рассмотрены понятия «дискурс» и «рекламный дискурс», подробно проанализированы тексты коммерческой рекламы советского и современного периода на предмет лингвокультурологических особенностей. В результате проведенного анализа автором были выявлены общие и особенные лингвокультурные черты советской и современной рекламы, которые напрямую связаны с внешними факторами (политическими, историческими, экономическими и т.п.). Так, в советский период главной целью рекламы ввиду отсутствия конкуренции, было информирование населения 0 новых товарах и услугах. В связи с этим рекламировались не производители, а товары. По этой же причине использовались примитивные слоганы. В начале 90-х годов, в эпоху подражания Западу, тексты стали пестрить англицизмами. Начиная с 90-х годов реклама преследовала одну главную цель: продать. В то время как персонажи играли важную роль в создании рекламной культуры для потребителей, продукт всегда был на переднем плане. Так продолжалось до тех пор, пока не появилась онлайн-реклама, а вместе с ней и несколько важных изменений в развитии рекламы и персонализации.

Ключевые слова: рекламный дискурс, лингвокультурология, персонализация, императивы, олицетворение, отклонения.

зультат и есть текст» [4; с. 293].

Реклама вышла за рамки использования простых методов объявления о наличии товаров или услуг. Из-за растущей эффективности методов убеждения реклама прочно вошла в социальный дискурс в силу ее широкого распространения в обществе.

Рекламный дискурс проникает во все виды институциональной коммуникации благодаря своей тематически неограниченной природе, жанровой самобытности и склонности улавливать самые незаметные проявления постоянно меняющегося мира. Этот тип дискурса считается наиболее образцовым, поскольку он может отражать последние тенденции социолингвистических реалий в рамках одного слогана, который рассматривается как композиционный компонент рекламного текста и решающий элемент с коммуникативно-прагматической точки зрения.

Целью данной работы является выявление, анализ 
и сопоставление лингвокультурологических особенностей в текстах коммерческой рекламы советского и современного периода.

Для достижения поставленной цели нам предстоит решить следующие задачи:

1. рассмотреть понятия «дискурс», «рекламный дискурс»;

2. собрать материал и проанализировать тексты коммерческой рекламы советского и современного периода на предмет лингвокультурологических особенностей;

3. провести сопоставительный анализ выявленных особенностей рекламных текстов двух указанных временных периодов. Материал исследования составляют тексты коммерческой рекламы, производящейся и демонстрирующейся в СССР и РФ в период с 1980 по настоящее время на телевидении, радио, рекламных щитах, постерах, периодической печатной продукции и на других носителях. В ходе исследования также был проведен анализ рекламных материалов, доступных через официальные онлайн-ресурсы компаний.

В качестве методов исследования в данной работе используются анализ научной литературы, метод сплошной выборки, а также различные методы лингвистического анализа.

Говоря про научную базу по изучению рекламного дискурса, следует отметить работы таких исследователей как В.И. Карасик [5], Е.В. Куликова [6], Г.Г. Слышкин [7], В.Б. Кашкин [8] и др.

Особый интерес представляют работы зарубежных авторов.

Гай Кук [9] полагает, что, в то время как основной центр дискурсивного анализа сосредоточен на языке, он не имеет отношения к языку как таковому. Особое внимание он уделяет контексту общения: кто с кем общается и почему; в каком многообразии общества и ситуации; через какую среду; как развивались различные типы и акты общения, и как они соотносились друг с другом.

Анджела Годдард [10] в своей публикации «Язык рекламы» представляет практический опыт текстового анализа, фокусируется на письменных рекламных объявлениях, исследует дискурс между читателем и рекламой, рассматривает такие рекламные стратегии, такие как каламбур и коннотации, взаимосвязь между рекламой и культурой, а также опирается на литературную и лингвистическую теорию для анализа рекламных текстов.

Поль Брютио [11] в своих работах особое внимание уделяет лингвистическим особенностям рекламы, таким как семантические компоненты, орфография и словарный запас, а также проводит подробный анализ языковых форм и коммуникативных функций.

В СССР были свои особенности рекламы, что существенным образом наложило отпечаток на рекламный дискурс. Так, практически в отсутствии конкуренции рекламировались не производители, а товары. По этой же причине использовались примитивные слоганы. В рекламных текстах постоянно повторялись императивы: «пейте», «покупайте», «летайте». Наиболее часто встречающимся словом было слово «лучший».

В 1990-е годы в стране появляются рыночные отношения, и реклама приобретает большее значение. Появляется конкуренция, следовательно, рекламные тексты начинают включать в себя названия компаний, становятся более содержательными и изощренными.

Главная тенденция того времени - выделить свой товар, свою марку. Превосходство («самый-самый») встречается почти в каждом рекламном тексте.

Прилагательные в сравнительной и превосходной степени часто и широко использовались в рекламе того времени.

«Амата. Самый добрый домашний компьютер».

El Gusto. Самый горячий кофе.

Так, логистическая компания DHL, пришедшая на российский рынок еще в конце 1980-х гг., неоднократно подчеркивала свое преимущество в рекламных текстах, что она более доступна и легко доступна, с помощью слов «больше» и «самая крупная». У тех, кто читал эту рекламу, складывалось впечатление, что DHL - правильный выбор для них, потому что у нее больше направлений, чем у других компаний.

«Цвет как никакой другой. <...> Непохожий на другой» - выражение из текста рекламы отечественных телевизоров Эриссон. Здесь очевиден принцип метонимии. Слово «цвет» заменяет все цвета или, как правило, качество изображения. Все высказывание основано на концепции сравнения, поскольку изображение телевизоров Эриссон сравнивается со всеми изображениями телевизоров других производителей.

Подзаголовок «Новый ЖК-телевизор Эриссон LED» просто добавляет название продукта, используя слово «новый», чтобы передать ощущение беспрецедентной технологии.

Такая распространенная в СССР грамматическая особенность рекламного языка как использование повелительных и повествовательных предложений, которые 
побуждают потенциальных клиентов увидеть продукт, сохранилась и в 90-е годы. Копирайтеры использовали императивы для создания ощущения, что один человек разговаривает с другим, потому что вся реклама побуждает нас к какому-либо действию.

Существуют определенные группы глагольных элементов, которые особенно часто встречаются в повелительных предложениях в рекламных текстах:

- предметы, связанные с приобретением товара: получить, купить, просить, выбирать и т.д.

- предметы, связанные с потреблением или использованием продукта: есть, пробовать, использовать, наслаждаться и т.д.

- предметы, которые служат призывом к уведомлению: смотрите, запоминайте, убедитесь и т.д.

Но в отличие от рекламных текстов эпохи СССР, самым важным моментом рекламного объявления стало заглавное слово, которое является ключевым словом, например, новый, сэкономить, выиграть, попробовать, получить или купить. Заголовок добавлял акцент к определенному предложению, позволяя ему стоять отдельно в одной строке, или приукрашивая его. Такое слово использовалось для того, чтобы зацепить читателя, предлагая обещание, раскрывая некую тайну или создавая двусмысленность, которую можно разрешить, только продолжая читать рекламный текст. Некоторые рекламные тексты иногда образовывали последовательность множества прилагательных в одной фразе, характеризующей существительное (например, «Прохладный сливочно-мятный оттенок с медленным бархатистым свежим маслянистым послевкусием» (реклама мороженого «Кзо»)).

Создатели рекламы часто нарушают языковые правила, поскольку большинство рекламных объявлений приближено к повседневному разговору, существует относительно свободный выбор типов предложений, поскольку их единственная цель - донести рекламируемый продукт привлечь внимание, подчеркнув его качества наиболее привлекательным образом.

С конца 90-х годов так называемый эффект «отклонения» стал широко распространенной аксиомой. На лингвистическом уровне такого эффекта можно достичь, нарушив условности использования языка, такие как неправильное написание, неологизмы, каламбур, грамматические ошибки, рифмы, семантические отклонения, а также использование несоответствующего или необычного контекста языка. Тем не менее, несмотря на отклонение от этих правил естественного языка, рекламные объявления по-прежнему читабельны, их можно связно понять.

Кук [9] различает две формы отклонения: внешнее отклонение (отклонение от внешней нормы) и внутреннее отклонение (отклонение от описания, распознанного в тексте). Это явление особенно характерно для рекламы, «жанра, в котором такие внешние отклонения, как графологические инновации, орфографические ошибки, каламбур, грамматичность, устойчивая двусмысленность и т.д., становятся настолько ожидаемыми, что в некотором смысле наиболее действительно отклоняющаяся реклама - это реклама, которая вообще не имеет внешних отклонений.

Рекламные объявления отклоняются от ожидаемых норм использования языка. Например, структура предложения: глаголы в рекламе появляются в настоящем времени («Люди говорят», МТС). Рекламодатели используют настоящее время чтобы создать более яркий эффект, показать неформальность или показать чувство дружелюбия между говорящим и слушателем («Мы заботимся о вас», Tefal; «Мы работаем, вы отдыхаете», Indesit; «Мы угадываем желания», Ariston).

В конце 2000-х и вплоть до настоящего времени в рекламном дискурсе наблюдается возврат к ценностям семье, природе, впечатлениям (путешествия, машины), искусство («искусство вдохновляет технологии»), с намеком на внутренние чувства (например, реклама йогуртов «Активиа» - «Важно то, что внутри», реклама сока «Добрый» - «Растим добро», «Поделись добротой»).

Отсылку к ценностям семьи, природы, традиций мы наблюдаем в рекламе ОАО «Газпром», о чем свидетельствует аудиоряд - «Сила тайги», «Сила реки», «Сила гор», «Сила духа», «Сила воли», «Сила красоты», «Сила семьи», «Сила традиций», «Сила движения», «Сила света», «Сила Сибири».

В данном примере мы наблюдаем такое частое для рекламных текстов 2000-х годов явление как параллелизм.

Следует отметить, что параллелизм может быть не только графологическим, фонологическим и грамматическим, но также семантическим и дискурсивным. Эти разные уровни параллелизма могут сосуществовать в одном тексте. Во всех строках рекламного текста, приведенного выше, есть графологический параллелизм между фразами «Сила тайги», «Сила реки» и т.д., потому что они начинаются с одного и того же слова.

Параллелизм означает повторение языковых моделей, таких как предложения, фразы и выражения. В случае синонимичного или тавтологического параллелизма синтаксические параллельные словосочетания констатируют одно и то же по содержанию.

Рассмотрим еще один пример рекламного текста, типичного для 2000-х годов, - реклама средств для ухода за волосами «Керастаз»: «Гамма для преображения волос, в 
основе которой лежат драгоценные масла, а в сердце инновационная формула».

В данном примере одним очевидным образным приемом является персонификация термина, используемого в основном в литературе для обозначения фигуры речи, которая включает прямое упоминание неодушевленного предмета, как если бы это было живое существо, часто обладающее специфическими человеческими качествами.

В рекламе «Керастаза» олицетворяется продукт (масло для волос), как если бы это было живое существо. Применяя слово «сердце», создается образ живого организма.

Олицетворение, наделение неодушевленных объектов признаками и свойствами, присущими живым существам, аналогичным образом часто встречается в различных рекламных текстах. Наиболее яркие примеры: «гостеприимный кроссовер» (об автомобиле «LADA XRAY»), «надежный немец» (об автомобиле BMW), «помощник» (о моющем средстве «Mr.Propper», о пылесосе «Tomas»).

Если в постсоветское время, в 90-е годы, в рекламных текстах было явное подражание западной культуре, зарубежной моде, слоганы и тексты пестрили англицизмами, то в 2000-е годы порой наблюдается обратное явление. Даже встречается противопоставление западной культуре слоганам, навязанным западным брендам. Так, в рекламе кваса «Никола» обыгрывалось противопоставление русского народного напитка западной Кока-Коле.

В тексте рекламы кваса «Никола» можно встретить игру с созвучием. На самом деле это распространенное явление, используемое в рекламных кампаниях. В данном примере слово «Никола» звучит как «Не кола» в значении (отрицания - «не»)). Это может означать, что в данном напитке отсутствуют типичные качества колы. Цель такова: люди могут подумать о другой марке напитка, который может не иметь физических характеристик колы, которую они знают.

В 2000-е годы с появлением Google AdWords, рекламной платформы, позволяющей настраивать таргетинг рекламы на основе истории поиска в Google и предпочтений пользователей при просмотре, изменяются и требованиям к рекламным текстам в интернете. Чтобы поисковые системы выдавали рекламу на верхних строках, должна быть определенная частота повторяемости ключевых слов. Из-за этого тексты зачастую переставали быть «красивыми», и им стало присуще такое явление как тавтология.

И только несколько лет назад данная ситуация ста- ла меняться: стала важна персонализация. Рекламные тексты перестали быть набором слов, в них начали появляться образы, идеи (реклама Mitsubishi Outlander про сказки на ночь, красота природы и незабываемые впечатления в рекламе LADA Vesta SW Cross).

Как мы видим на конкретных примерах, в рекламных текстах используются разнообразные речевые средства выразительности и способы подачи информации.

В результате проведенного анализа нами выявлены общие и особенные лингвокультурные черты советской и современной рекламы.

В СССР были свои особенности рекламы, что существенным образом наложило отпечаток на рекламный дискурс.

В советский период, пожалуй, главной целью рекламы ввиду отсутствия конкуренции, было информирование населения о новых товарах и услугах. В связи с этим рекламировались не производители, а товары. По этой же причине использовались примитивные слоганы.

В начале 90-х годов, в эпоху подражания Западу, тексты стали пестрить англицизмами. С расцветом рекламы в конце 90-х - начале 2000-х годов профессионалы начали придумывать грандиозные идеи рекламных текстов, опираясь на психологию и большие данные, используя различные лингвистические приемы, представленные на лексическом, грамматическом, стилистическом уровнях.

В рекламных текстах в 2000-е годы уже практически не возможно встретить императивных конструкций, призывов к действию. Вместо того, чтобы напрямую рассказывать потребителям о продукте или о том, что компании хотят, создаются более «тонкие», «цепляющие» тексты и образы, часто с какой-либо историей, позволяющие аудитории самой интерпретировать значения для себя. Такой подход естественным образом меняет отношение к бренду, влияет на то, как люди запоминают его и обрабатывают представленную информацию, поскольку им на самом деле приходится думать, а не принимать то, что им говорят, за чистую монету.

Начиная с 90-х годов реклама преследовала одну главную цель: продать. В то время как персонажи играли важную роль в создании рекламной культуры для потребителей, продукт всегда был на переднем плане. Так продолжалось до тех пор, пока не появилась онлайн-реклама, а вместе с ней и несколько важных изменений в развитии рекламы и персонализации.

В эволюции рекламы за прошедшие годы произошли важные вехи, поскольку ей приходилось постоянно приспосабливаться и меняться, чтобы соответствовать 
новым средам и аудиториям. Что наиболее важно, на протяжении истории она становилась более персонализированной. Единственная среда, которая оказала наибольшее влияние на эволюцию и персонализацию рекламы - это Интернет и его способность собирать миллиарды точек данных о пользователях.

\section{ЛИТЕРАТУРА}

1. Beasley, R and Danesi, M. 2002. Persuasive Signs. Berlin. New York.

2. Wodak, R. 2007. Pragmatics and critical discourse analysis. A cross-theoretical inquiry. Pragmatics and Cognition 15/1 (Special issue'Pragmatic Interfaces'): $203-234$.

3. Тюрина С.Ю. 0 понятиях рекламный дискурс и рекламный текст // Вестник ИГЭУ, 2009. Вып. 1. С. 75-77.

4. Кибрик А.Е. Очерки по общим и прикладным вопросам языкознания. Гл. 19. Эскиз лингвистической модели текстообразования. - М., 1992. - С. $287-301$.

5. Карасик В.И. О типах дискурса [Текст] // Языковая личность: институциональный и персональный дискурс: Сб. науч. тр. - Волгоград, 2000. - С. 5-20.

6. Куликова Е.В. Языковая Специфика Рекламного Дискурса / Вестник Нижегородского университета им. Н.И. Лобачевского, 2008, № 4, с. $197-205$.

7. Слышкин Г.Г. Дискурс и концепт (о лингвокультурном подходе к изучению дискурса) [Текст] // Языковая личность: институциональный и персональный дискурс: Сб. науч. тр. - Волгоград: Перемена, 2000. - С. 38-45.

8. Кашкин В.Б. Сопоставительные исследования дискурса [Текст] // Концептуальное пространство языка. - Тамбов: ТГУ, 2005. - С. 337-353.

9. Cook, G. 2001. The Discourse of Advertising. London and New York.

10. Goddard, A. 1998. The Language of Advertising. London and New York.

11. Bruthiaux, P. 1996. The Discourse of Classified Advertising. Oxford University Press.

(c) Нгуен Тхи Ван Ань (vananhrussia95@gmail.com).

Журнал «Современная наука: актуальные проблемы теории и практики»

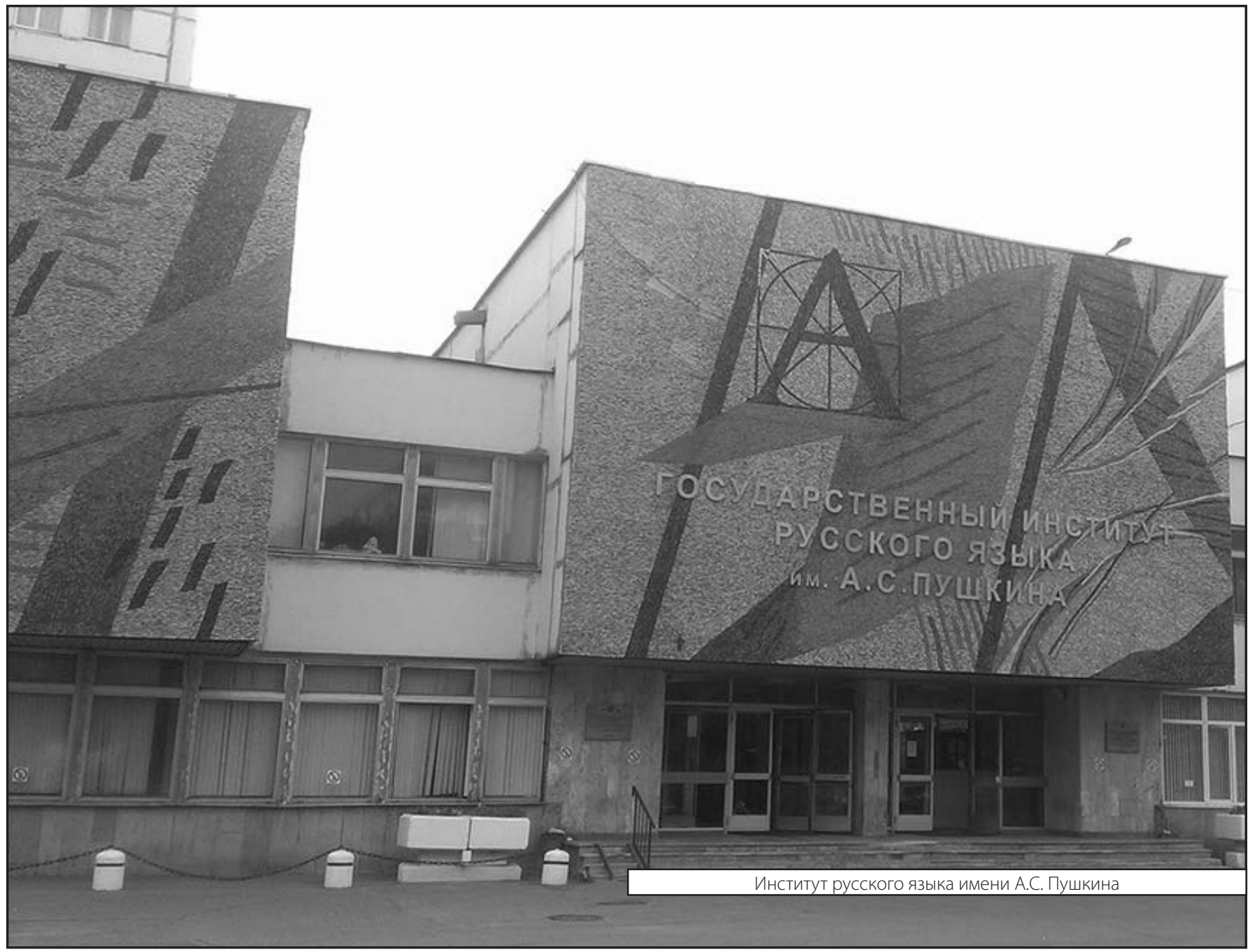

